\title{
PAEDIATRIC RENAL MASS: A CASE REPORT
}

\section{HOWLADER FAZLUL KARIM ${ }^{1}$, MD. MONOWARUL ISLAM ${ }^{1}$, SK. AMIRUL ISLAM ${ }^{1}$, SHUVENDRA NATH NAG ${ }^{1}$, MD. SIDDIQUR RAHMAN ${ }^{1}$ MOHAMMAD MURAD CHOWDHURY ${ }^{1}$, PRANASHIS SAHA $^{1}$}

${ }^{1}$ Department of Uro-Oncology, NICRH, Mohakhali, Dhaka-1212

\begin{abstract}
More than $90 \%$ of malignant renal tumors encountered in children are Nephroblastoma. Renal Cell Carcinoma is extremely rare in children but in children older than 5 years with renal masses it is very important to suspect diagnosis. We present a 6 years old child primarily presented with abdominal mass and haematuria. The mass was described by ultrasonography \& computer tomography as Wilms' Tumour which is commonest before 5 years of age with peak age of presentation is 3 years of life. Surgery is the best treatment and prognosis is favorable when tumour is localized and completely eradicated. In our case no adjuvant therapy was given nephrectomy.
\end{abstract}

Bangladesh J. Urol. 2017; 20(2): 102-104

\section{Introduction}

Renal cell carcinoma $(R C C)$ is extremely rare in children [1].

Incidence of this tumor in childhood is estimated to be $0.1-0.3 \%$ of all the neoplasm and $1.8-6.3 \%$ of all the malignant renal tumors [2,3].Several factors could influence prognosis, including stage, grade, histology, symptomatic presentation, and performance status. Among these, tumors stage is the most important predictor of disease prognosis for RCC [4]. No treatment protocols have been defined for children with RCC. Surgery is the mainstay of treatment and results in cure when the tumor is localized and completely resected [1]. The importance of radiotherapy and immunotherapy is not clear and different chemotherapy regimens showed minimal activity when tested in clinical trials. Here we present a 6 yrs old patient with RCC presenting with abdominal mass and hematuria.

\section{Case Report}

A 6-year-old boy presented with palpable mass \& macroscopic hematuria. The renal ultrasonography and CT urography showed right renal mass of $6.6 \times 6.8 \mathrm{~cm}$. There was no metastatic evidence in the imaging tools. Patient underwent transperitoneal radical nephrectomy of right kidney. The tumor has $7 \mathrm{~cm}$ in greatest diameter, the renal capsule was intact, and there was no tumor

Correspondences: Dr. Howlader Fazlul Karim, Department of Uro-oncology, National Institute of Cancer Research and Hospital (NICRH), Mohakhali, Dhaka-1212. thrombus in the renal vein or inferior vena cava. Histopathology revealed RCC - papillary type, Fuhrman nuclear grade- II. The postoperative course was uneventful. Extensive literature review regarding such cases revealed there occurs translocation in Xp11.2 region involving TFE-3 gene in a good proportion of pediatric RCC, such patients' present special subset of papillary RCC. But here in our settings we are unable to have such important cytogenetic test yet. As our patient has an early stage RCC, this young boy needs close follow-up, therefore he will be closely monitored for the issues regarding recurrence, distant metastasis or second tumour in the opposite kidney.

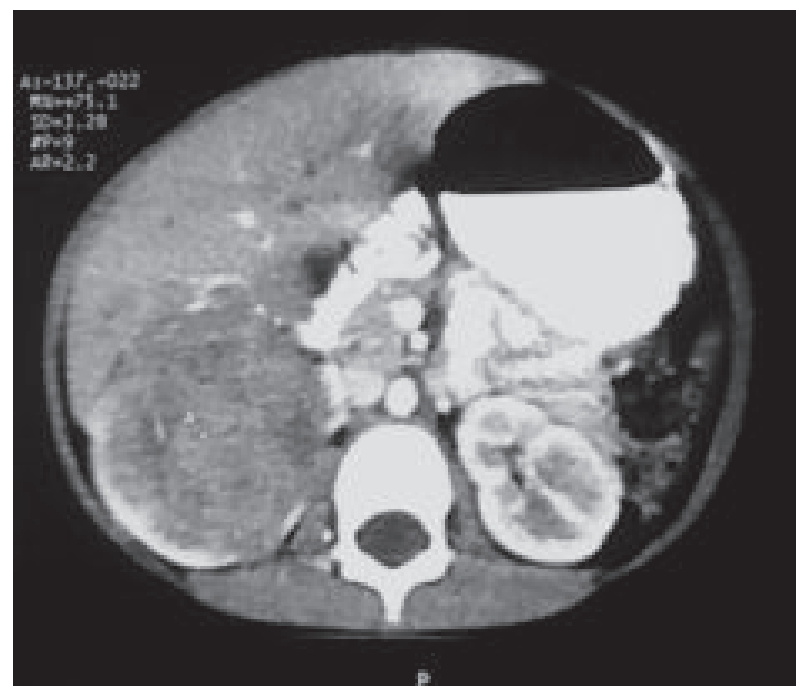

Figure 1: CT image showing heterogeneous 


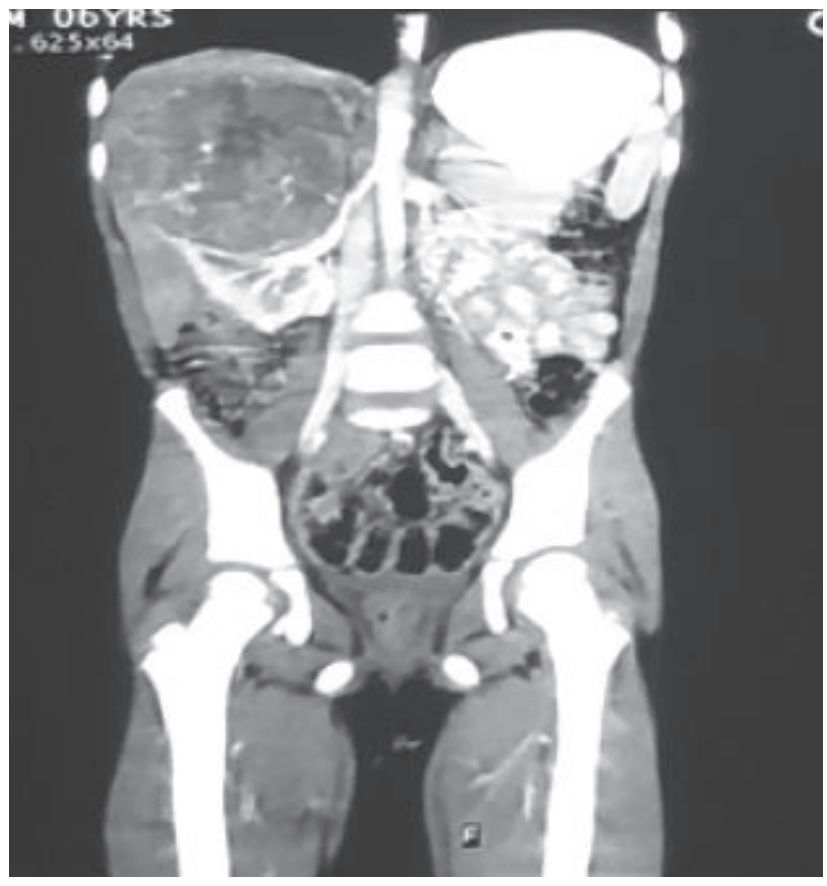

Figure 2: Frontal reconstruction of Right renal mass (Axial view). CT images- Right renal mass.

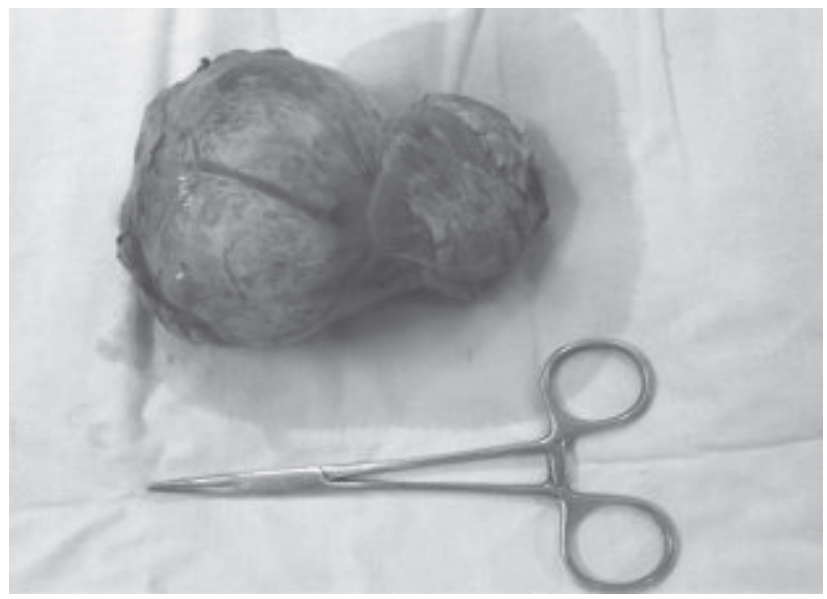

Figure 3: Image objectifying the nephrectomy piece

\section{Discussion}

Literature revealed that renal cell carcinoma corresponds to $1.4 \%$ of renal tumors in patients under 4 years old, $15.2 \%$ between 5 and 9 years and $52.6 \%$ between 10 and 15 years old [2]. Currently, about $50 \%$ to $68 \%$ of RCC patients are diagnosed incidentally [5]. The most common form of presentation of RCC in children is macroscopic hematuria and abdominal or flank pain. Other less frequent symptoms are palpable abdominal mass, anemia, and fever [6]. Palpable mass occurs in $38 \%$, hematuria in $38 \%$ and abdominal pain in $50 \%$, with the classic triad being found in only $6 \%$ of cases
[7]. Stachowicz-Stencel et al. reported that $52.4 \%$ of pediatric RCC cases were asymptomatic and diagnosed during routine examinations [8]. In our case diagnosis was done in the exploration of palpable abdominal mass and hematuria.Metastases occur in lungs (40-65\%), liver (35-57\%), bones (10-42\%) or bladder, brain or pleura (7$15 \%)$ [9].

Because of the resistance of RCC to systemic therapies and radiotherapy, surgical excision is the main stay of treatment. The completeness of the surgical resection has been shown to be a significant prognostic factor, with survival rates as low as $10 \%$ after incomplete resection [10]. The effects of chemotherapy, including immunotherapy, are unclear. Postoperatively, adjuvant radiotherapy and chemotherapy have been used in patients with higher-grade tumors. Although immunotherapies with interferon or interleukin and newer biological modifier as tyrosin kinase inhibitors for the treatment of advanced cases have been reported, the beneficial effects of these treatments are uncertain in children because of the lack of any prospective randomized studies [11]. Five years survival is more than $90 \%$ for patients with stage $1,50-80 \%$ for patients with stages 2 and 3 and less than $10 \%$ for stage 4 [7]. Patient age, tumor size, histological pattern, and vascular invasion have all been reported to be the predictors of outcome. Most recurrences and deaths usually occur within the first 2 years after diagnosis, although late recurrences are frequent [1]. Geller et al. suggested that children and adults with RCC have similar overall survival rates [12]. Furthermore, they reported that children with lymph node-positive RCC in the absence of distant metastatic disease had relatively favorable long-term prognoses compared with adults [12]. Geller and Dome conclude that lymphadenectomy in the absence of clinical or radiographic suspicion for nodal involvement confers no benefit [13]. Tumor stage appears to be the most important factor for the survival. The patients with a localized stage (stages 1 and 2) have the best prognosis [10]. Whatever the stage, patients need long-term follow-up after being treated for pediatric RCC.

\section{Conclusion}

$\mathrm{RCC}$ is rare in children, it is very important to suspect diagnosis in children older than 5 years with renal masses as the diagnostic and therapeutic approach differs from that for Wilms' tumor. Surgery is the best treatment and prognosis is better when the tumor is limited and completely removed. 


\section{References}

1. Indolfi P, Terenziani M, Casale F, Carli M, Bisogno $G$, et al. (2003) Renal cell carcinoma in children: $A$ clinicopathologic study. J Clin Oncol 21: 530-535.

2. Selle B, Furtwangler R, Graf N, Kaatsch P, Bruder E, et al. (2006) Population-based study of renal cell carcinoma in children in Germany, 1980-2005: More frequently localized tumours and underlying disorders compared with adult counterparts. Cancer 107: 2906-2914.

3. Varan A, Akyuz C, Sari N, Buyukpamuku N, Caaylar M, et al. (2007) Renal cell carcinoma in children: experience of a single center. Nephron Clin Pract 105: c58-c61.

4. Kontak JA, Campbell SC (2003) Prognostic factors in renal cell carcinoma. Urol Clin North Am 30: 467-480.

5. Hofbauer SL, de Martino M, Seemann C, Zamani $\mathrm{N}$, Lucca I, et al. (2014) Associations between presenting symptoms, clinicopathological parameters, and prognosis in a contemporary series of patients with renal cell carcinoma. Korean J Urol 55: 505-510.

6. Estrada CR, Suthar AM, Eaton SH, Cilento BG (2005) Renal cell carcinoma: Children's hospital Boston experience. Urology 66: 1296-1300.
7. Bruder E, Passera O, Harms D, Leuschner I, Ladanyi M, et al. (2004) Morphologic and molecular characterization of renal cell carcinoma in children and young adults. Am J Surg Pathol 28: 1117-1132.

8. Stachowicz-Stencel T, Bien E, Balcerska A, Godzinski J, Synakiewicz A, et al. (2011) Diagnosis and treatment of renal cell carcinoma in children: a report from the Polish pediatric rare tumor study group. Klin Padiatr 223: 138-141.

9. Carcao MD, Taylor GP, Greenberg ML, Bernstein ML, Champagne M, et al. (1998) Renal-cell carcinoma in children: a different disorder from its adult counterpart? Med Pediatr Oncol 31: 153-158.

10. Aronson DC, Medary I, Finlay JL, Herr HW, Exelby PR, et al. (1996) Renal cell carcinoma in childhood and adolescence: a retrospective survey for prognostic factors in 22 cases. J Pediatr Surg 31: 183-186.

11. Motzer RJ, Bander NH, Nanus DM (1996) Renalcell carcinoma. N Engl J Med 335: 865-875.

12. Geller JI, Dome JS (2004) Local lymph node involvement does not predict poor outcome in pediatric renal cell carcinoma. Cancer 101: 15751583.

13. Silberstein J, Grabowski J, Saltzstein SL, Kane CJ (2009) Renal cell carcinoma in the pediatric population: results from the California cancer registry. Pediatr Blood Cancer 52: 237-241. 